\title{
ENUNCIADOS DOS JUIZADOS ESPECIAIS FAZENDÁRIOS DO RIO DE JANEIRO: DESAFIOS NA GARANTIA DE DIREITOS
}

Statements of the Special Courts of Public Treasury of Rio de Janeiro: Challenges to the guarantee of rights

${ }^{1}$ Universidade Federal do Rio de Janeiro. Rio de Janeiro/RJ, Brasil.

Correspondência: Luciana Simas. E-mail: lucianasiams06@gmail.com

Recebido: 30/04/2018. Revisado: 13/08/2018. Aprovado: 14/08/2018. 


\section{RESUMO}

A judicialização da saúde, nas últimas décadas, tem produzido normas, diretrizes e ações que materializam uma interseção entre os campos da saúde e do direito, em diferentes contextos. O objetivo deste artigo é analisar os recentes enunciados jurisprudenciais dos Juizados Especiais Fazendários no Tribunal de Justiça do Rio de Janeiro, com o intuito de perceber as implicações dessas diretrizes para a garantia de direitos, em especial com relação ao fornecimento de medicamentos pelo Sistema Único de Saúde. Serão identificados, inicialmente, três momentos históricos relacionados às demandas judiciais para acesso a produtos e serviços de saúde; e, a seguir, serão problematizadas as determinações previstas nos enunciados, em especial no tocante à responsabilidade solidária, com vistas à efetividade do acesso à saúde e à justiça.

\section{Palavras-Chave}

Direito à Saúde; Judicialização da Saúde; Poder Judiciário; Sistema Único de Saúde.

\section{ABSTRACT}

The judicialization of health in recent decades has produced norms, guidelines and actions that materialize an intersection between the fields of Health and Law, in different contexts. The purpose of this paper is to analyze the recent jurisprudential statements of the Special Courts of Public Treasury at the Rio de Janeiro Court of Justice, in order to understand the implications of these guidelines in the guarantee of rights, especially with regard to the supply of drugs by the Brazilian Unified Health System. First, three historical moments related to the claims for access to health products and services will be identified; and after that, the determinations contained in those statements will be discussed, especially with regard to joint liability, having in mind the effectuation of the access to health and justice.

\section{Keywords}

Brazilian Unified Health System; Health's Judicialization; Judiciary; Right to Health. 


\section{Introdução}

A judicialização da saúde, nas últimas décadas, tem produzido normas, diretrizes e ações que materializam a interseção entre os sistemas de saúde e justiça, em diferentes contextos. Os enunciados jurisprudenciais expressam um tipo de interlocução a ser analisado com foco na efetividade mais ampla possível do direito à saúde.

O Tribunal de Justiça do Estado do Rio de Janeiro (TJRJ) editou, em dezembro de 2017, um conjunto de enunciados referentes à atuação dos Juizados Especiais Fazendários (JEF), por meio do Aviso Conjunto TJ/COJES n. 15. Foram mencionadas diversas questões de direito sanitário, como o fornecimento de medicamentos pelo Sistema Único de Saúde (SUS). O objetivo do presente trabalho é analisar esses recentes enunciados, com o intuito de perceber as implicações dessas diretrizes para a garantia de direitos, em especial na discussão da solidariedade entre os entes federativos.

O fenômeno da judicialização é complexo e multifacetado, envolvendo inúmeros vetores, desde a mobilização social até a influência econômica da indústria farmacêutica e de produtos de saúde. Desse modo, serão identificados sucintamente três momentos históricos relacionados às demandas judiciais para acesso a produtos e serviços de saúde, para fins de contextualização do debate. A seguir, serão problematizados diferentes aspectos do conjunto de enunciados, que refletem mudanças no parâmetro decisório, no sentido de inserir argumentos da gestão relativos à configuração do SUS.

\section{A judicialização em três atos}

Os debates acerca da judicialização se perpetuam há anos, refletindo o protagonismo do sistema judicial, caracterizado em diversos países a partir do final da década de $1980^{1}$. Especificamente no tocante às demandas por acesso a serviços e produtos de saúde, identificadas no contexto brasileiro pós-Constituição de 1988 (CF/1988), percebe-se uma primeira "onda" de processos judiciais correlacionados a questões ligadas à Aids que pleiteavam medicamentos antirretrovirais, internações, exames para pessoas com HIV/Aids, controle das transfusões e assistência a hemofílicos, em uma luta árdua contra o preconceito ${ }^{2}$.

A estratégia da litigância repercutiu nas décadas seguintes para outros movimentos sociais, organizados ou não, e no início dos anos 2000 inquietou ainda

\footnotetext{
${ }^{1}$ Conforme SANTOS, B.S. Para uma revolução democrática da justiça. 3. ed. Rio de Janeiro: Cortez, 2012; e VIANNA, L.W. et al. A judicialização da política e das relações sociais no Brasil. Rio de Janeiro: Revan, 1999. 2SCHEFFER, M. Coquetel: a incrível história dos antirretrovirais e do tratamento da Aids no Brasil. São Paulo: Hucitec; Sobravime, 2012; e MESSEDER, A.M.; OSORIO-DE-CASTRO, C.G.S.; LUIZA, V.L. Mandados judiciais como ferramenta para garantia do acesso a medicamentos no setor público: a experiência do Estado do RJ, Brasil. Cad. Saúde Pública, São Paulo, v. 21, n. 2, p. 525-534, mar./abr. 2005. Disponível em: <http://www. med-informatica.net/OBSERVAMED/PFNyLeyMedicamento/Costos_medicamentos_brazil.pdf>.
} 
mais os gestores públicos, na medida em que alguns rumos das políticas de saúde passaram a ser fortemente influenciados pelas demandas judiciais. A implantação da Política Nacional de Medicamentos ${ }^{3}$ tentou alinhar a preocupação orçamentária com as responsabilidades sanitárias quanto à segurança e eficácia dos fármacos. Nesse segundo momento da judicialização, ampliaram-se as demandas individuais por medicamentos com relação a diversas doenças, mas ainda sem a estrutura das defensorias em todos estados. As respostas dos gestores, de modo geral, apresentavam-se juridicamente incipientes ${ }^{4}$, porém já defendendo a titularidade coletiva do direito social à saúde e refutando a possibilidade de tutela de prestação individual não prevista nas políticas ${ }^{5}$.

Identifica-se uma busca de interlocução entre os atores envolvidos, como a audiência pública no Supremo Tribunal Federal (STF) em 2009, e as recomendações do Conselho Nacional de Justiça (CNJ) no sentido de apoio técnico sanitário à magistratura - com a formação dos Núcleos de Assessoria Técnica (NAT) nos tribunais locais, compostos por funcionários das secretarias de saúde dos estados ${ }^{6}$. Ao final desse período, apresentam-se novas premissas aos argumentos dos tribunais, com desafios de harmonização das dimensões individuais e coletivas do direito à saúde ${ }^{7}$, essenciais para a compreensão da formulação dos enunciados do TJRJ.

O poder simbólico do direito é ordenado a partir de um habitus ${ }^{8}$ e não apenas caracteriza uma linguagem própria, como também envolve uma racionalidade científica específica. O mesmo ocorre com a saúde pública, que se constitui com saberes e regras particulares, legítimas ou legalmente construídas. O diálogo entre

${ }^{3}$ BRASIL. Ministério da Saúde. Portaria n. 3.916, de 30 de outubro de 1998. Aprova a Política Nacional de Medicamentos. Disponível em: <http://bvsms.saude.gov.br/bvs/saudelegis/gm/1998/ prt3916_30_10_1998.html>. Acesso em: 19 set. 2018.

${ }^{4}$ Aspecto observado e descrito em pesquisa de PEPE, V.L.E. et al. Caracterização de demandas judiciais de fornecimento de medicamentos "essenciais" no Estado do RJ, Brasil. Cad. Saúde Pública, São Paulo, v. 26, n. 3, p. 461-471, 2010. Disponível em: <http://www.scielo.br/pdf/csp/v26n3/04.pdf>. http://dx.doi. org/10.1590/S0102-311X2010000300004.

${ }^{5}$ BARROSO, L. R. Da falta de efetividade à judicialização excessiva: direito à saúde, fornecimento gratuito de medicamentos e parâmetros para a atuação judicial. Revista de Direito - v. 63, p. 320-344, 2008. Disponível em: <http://www.rj.gov.br/c/document_library/get_file?uuid=ddd94821-04ab-4710-a3c1Ob61193e87ac\&groupld=132971>. Acesso em: 03 ago. 2018.

${ }^{6}$ Pesquisados em profundidade por VENTURA, M. O processo decisório judicial e a assessoria técnica: a argumentação jurídica e médico-sanitária na garantia do direito à assistência terapêutica no Sistema Único de Saúde. Tese (Doutorado em Ciências na área de Saúde Pública) - ENSP/Fiocruz, Rio de Janeiro, 2012. Disponível em: <http://bvsms.saude.gov.br/bvs/publicacoes/premio2012/doutorado/Miriam\%20 Ventura\%20da\%20Silva.pdf>.

${ }^{7}$ SARLET, I.W. A titularidade simultaneamente individual e transindividual dos direitos sociais analisada à luz do exemplo do direito à proteção e promoção da saúde. Direitos Fundamentais e Justiça, n.10, p. 205-227, jan. 2010.

${ }^{8} \mathrm{~A}$ noção de habitus, na interface entre o direito e a saúde, exprime "o lado ativo do conhecimento prático"; um conhecimento adquirido como um capital incorporado, quase postural, capaz de romper com o paradigma de um moralismo abstrato, puro e formal. Propõe-se, com esse conceito, uma análise científica sobre o "fazer funcionar [...] a respeito de um objeto diferente, o modo de pensamento que dele se exprime". BOURDIEU, P. O poder simbólico. Trad. Fernando Tomaz. 3. ed. Rio de Janeiro: Bertrand Brasil, 2000. p.61 e 64 . 
esses campos, a partir da pauta das demandas judiciais, foi conquistado por diversos atores e tem amadurecido interdisciplinarmente ao longo das últimas décadas. Atualmente, podemos vislumbrar um terceiro contexto, no qual diferentes setores conseguem articular conjuntamente normas, diretrizes e ações.

Fazem parte dessa nova conjuntura: o Fórum da Saúde do CNJ, para monitoramento e resolução das demandas de assistência à saúde, com seus comitês nacional e estaduais ${ }^{9}$; a ampliação do acesso às defensorias estaduais e da União; e as experiências de mediação e/ou resolução extrajudicial dos conflitos, como a Câmara de Resolução de Litígios em Saúde (CRLS), no Município do Rio de Janeiro, composta por diferentes membros da gestão de saúde e do sistema de Justiça. Esse cenário recente corresponde a uma terceira fase da judicialização, por ter um discurso estatal mais refinado, a partir de uma rearticulação dos atores-chave. Os enunciados publicados pelo TJRJ, analisados a seguir, materializam esse entrelaçamento de lógicas complementares na discussão acerca do direito à saúde. Todavia, ainda são poucas as pesquisas acerca dos efeitos desses mecanismos, diversos do momento anterior.

\section{Problematização de enunciados, com ênfase na responsabilidade solidária}

A aprovação dos enunciados relativos aos Juizados Especiais objetivou "constituir jurisprudência predominante" e, no que concerne aos pedidos por medicamentos, são orientações inéditas.

De acordo com o primeiro enunciado, no caso de medicamentos, tratamentos ou insumos previamente padronizados pelo SUS, o reivindicante deverá propor a ação judicial "em face do ente vinculado ao fornecimento em conformidade com a política pública existente e as atribuições administrativas fixadas, não havendo que se falar em solidariedade entre os entes federativos nesse caso". Foram valorizadas as delimitações administrativas da política pública existente, e mitigada a responsabilidade solidária, impedindo o demandante de optar por propor a ação contra dois ou mais entes da Federação.

Nas solicitações de fornecimento de medicamentos, tratamentos ou insumos não padronizados pelo SUS, manteve-se a premissa da responsabilidade solidária, com a possibilidade de o proponente da ação judicial optar qual ou quais devedores serão acionados diante da conduta e dos danos demonstrados.

O comando constitucional da solidariedade é um instituto estruturante do SUS, voltado para a garantia máxima do direito fundamental à saúde e a responsabilização dos entes federativos. Tem sido aplicado historicamente na demanda judicial

${ }^{9}$ BRASIL. Conselho Nacional de Justiça. Portaria n. 8, de 02 de fevereiro de 2016. Cria o Comitê Organizador do Fórum Nacional do Poder Judiciário para monitoramento e resolução das demandas de assistência à saúde. Disponivel em: <http://www.cnj.jus.br/busca-atos-adm?documento=3066>. Acesso em: 19 set. 2018. 
em saúde como um dispositivo de segurança diante de indefinições normativas, associadas a recusas discordantes e recorrentes dos entes estatais. Considerando-se a ausência ou insuficiência de integração entre os diferentes níveis de governo, não se pode desprezar a desassistência aos cidadãos, que costumeiramente se deparam com a falta de informações, de transparência e de serviços de saúde.

Por outro lado, a solidariedade pode gerar iniquidades e discrepâncias, principalmente orçamentárias nos municípios, sobrecarregados por diversas ordens judiciais ${ }^{10}$. Nesses casos, dificilmente se observa atuação política autônoma dos municípios/estados, que teriam a opção jurídica de cobrar a despesa realizada, em ações de regresso em face do ente federativo diretamente responsável.

O STF se posicionou em 2015, na Repercussão Geral do RE n. 855.178, considerando que a divisão de tarefas por conveniência administrativa não exclui a solidariedade ${ }^{11}$. Pesquisadores também se manifestaram, no sentido de que os pactos firmados, ainda que definidos em normas jurídicas, não podem excluir ou limitar a responsabilidade solidária derivada da competência comum, com vistas à proteção efetiva do direito à saúde. Segundo os argumentos do Núcleo de Pesquisa em Direito Sanitário da Universidade de São Paulo (NAP-DISA/USP) e do Centro de Estudos e Pesquisas de Direito Sanitário (Cepedisa) ${ }^{12}$, as enormes disparidades regionais e entre os próprios entes federativos legitimam a responsabilidade solidária, na medida em que as limitações financeiras, contingenciais ou não, podem impedir que um município ou estado disponibilize o produto ou serviço de saúde.

Se nenhuma norma infraconstitucional pode limitar o direito à saúde, igualmente não poderá fazê-lo uma determinação local do Judiciário, ainda que colegiada. Todavia, é possível utilizar criativamente outros mecanismos jurídico-processuais que alcancem um melhor resultado e cooper ação entre os entes vinculados na prestação jurisdicional, como uma ordem de preferência ou o chamamento ao processo no procedimento comum.

\footnotetext{
10PINTO, C.D.B.S.; OSORIO-DE-CASTRO, C.G.S. Gestão da Assistência Farmacêutica e demandas judiciais em pequenos municípios brasileiros: um estudo em MS. Saúde Debate, Rio de Janeiro, v. 39, n. esp., p. 171183, 2015. Disponível em: <http://www.scielo.br/pdf/sdeb/v39nspe/0103-1104-sdeb-39-spe-00171. pdf>. http://dx.doi.org/10.5935/0103-1104.2015S005152.

${ }^{11} \mathrm{~A}$ repercussão geral é um mecanismo processual que determina a aplicação do entendimento do STF aos demais recursos sobre o mesmo tema. No caso de divergência, a principal consequência será o juízo de retratação pelo órgão julgador, previsto no artigo 1.030, inciso II, do Código de Processo Civil. Como os enunciados do TJRJ com posicionamento diverso do STF são muito recentes, ainda não há discussão recursal nesse sentido; entretanto, provavelmente, essa questão despontará no plano da uniformização da jurisprudência.

${ }^{12}$ NAP-DISA/USP. Cepedisa. Opinião legal. São Paulo: USP, 2015. Disponível em <http://napdisa.prp.usp. br/wp-content/uploads/2016/12/OPINIAO-LEGAL-Competencia-Comum-Saude-final.pdf >. Acesso em: 19 abr. 2018.
} 
De todo modo, os enunciados ratificam orientação majoritária de que é necessário demonstrar a imprescindibilidade do tratamento solicitado e apresentar provas da ineficácia da opção terapêutica disponibilizada no SUS, associando-se as condições de vida da pessoa.

O Judiciário fluminense ressalvou a possibilidade de concessão de tutelas de urgência, em casos de medicamentos padronizados ou não, desde que haja indicação do NAT ou da CRLS. Entretanto, se fosse medicamento não padronizado, o processo deveria ser suspenso para apreciação da matéria pelo STJ. Esse aspecto do enunciado perdeu efeito quando, em 25 de abril de 2018, foi julgado o RE $n$. 1.657.156 - RJ, ratificando a possibilidade de fornecimento de medicamentos que não constem nas listas do SUS, desde que haja, em processos futuros ${ }^{13}$ :

1 - comprovação da imprescindibilidade ou necessidade do medicamento, por meio de laudo médico, bem como da ineficácia dos fármacos fornecidos pelo SUS;

2 - incapacidade financeira do paciente de arcar com o custo do medicamento; e

3 - registro prévio do medicamento na Agência Nacional de Vigilância Sanitária ${ }^{14}$.

Outra questão abordada diz respeito à substituição de medicamentos por outros no mesmo processo. Há uma súmula anterior do próprio TJRJ (n. 116/2006) que permite a substituição se o medicamento substituto for relativo à mesma doença, dando maior tranquilidade ao cidadão e prevenindo o ajuizamento de uma nova ação a cada alteração da prescrição médica. Todavia, na conjuntura atual, o tribunal afirma que esse indicativo não deve ser aplicável aos processos nos JEF, pois pode "acarretar violação à natureza tripartida do SUS, estendendo-se sem prévia instrução as atribuições administrativas dos entes federativos" e afrontar os princípios dos Juizados Especiais, como a celeridade e a ausência de perícias, diante da menor complexidade fática das demandas.

Por fim, o TJRJ reafirmou a impossibilidade de solicitação de uma marca específica a ser fornecida pelo ente público, se houver outras registradas e com

\footnotetext{
${ }^{13}$ Inovadora modulação dos efeitos, com consequências somente para casos ajuizados posteriormente ao julgamento. Também foi determinada a comunicação ao Ministério da Saúde e à Comissão Nacional de Tecnologias do SUS (Conitec), após o encerramento de cada processo, para a realização de estudos quanto à viabilidade de incorporação.

${ }^{14}$ SUPERIOR TRIBUNAL DE JUSTIÇA - STJ. Primeira Seção define requisitos para fornecimento de remédios fora da lista do SUS. 25/04/2018. Disponível em: <http://www.stj.jus.br/sites/STJ/default/pt_BR/ Comunica\%C3\%A7\%C3\%A3o/noticias/Not\%C3\%ADcias/Primeira-Se\%C3\%A7\%C3\%A3o-define-requisitospara-fornecimento-de-rem\%C3\%A9dios-fora-da-lista-do-SUS>. Acesso em: 27 abr. 2018.
} 
idêntica segurança, sob pena de afronta ao princípio da impessoalidade da Administração Pública.

O estudo identifica a resposta do Judiciário do RJ às dificuldades no tocante ao cumprimento da assistência farmacêutica integral, o que poderia contribuir para consolidação das pactuações dos entes federativos. Contudo, a fragmentação da dispensação dos medicamentos pode implicar dificuldades de acesso dos cidadãos, com efeitos práticos em relação à responsabilização dos entes federativos na consolidação de um sistema único com políticas voltadas à integralidade da assistência à saúde. Ademais, a quebra da responsabilidade solidária complexifica o procedimento de acesso à justiça.

Convém registrar que, no plano federal, a $3^{\text {a }}$ Turma do STJ proferiu uma solução conjugada com os interesses da saúde coletiva. No Recurso Especial n. 1.721.711/RJ, em 20 de abril de 2018, autorizou a entrada em domínio público (quebra da patente) do medicamento Soliris, viabilizando o acesso ao mercado de genéricos. A justificativa foi de que a questão jurídica extrapola a mera relação entre o Instituto Nacional da Propriedade Industrial e a empresa farmacêutica, pois "os efeitos do ato administrativo irradiam-se por todo o tecido social, não figurando razoável impor pesados encargos à coletividade em benefício exclusivo dos interesses econômicos da empresa recorrente". De maneira sutilmente diversa da postura do TJRJ, o STJ buscou assegurar o acesso à saúde e à justiça por meio da imposição de responsabilidades para o grande capital da indústria farmacêutica, contextualizando materialmente sua análise decisória.

\section{Considerações finais}

A produção jurisprudencial pode ser uma ferramenta importante para a garantia do direito à saúde. Todavia, também pode servir para a manutenção e/ou produção de injustiças. Portanto, para além de uma lógica simplista e maniqueísta, entendemos que, na atuação do sistema de justiça, é fundamental o diálogo democrático na construção de caminhos que efetivamente permitam o acesso universal, equânime e eficiente ao sistema público de saúde.

Os enunciados do TJRJ sugerem algumas transformações na articulação entre os poderes Executivo e Judiciário. Porém, almeja-se que, nesse processo socio-histórico de defesa do direito à saúde para toda a população, a atuação conjunta dos sistemas de Justiça e da saúde se fortaleça em linhas amadurecidas de cooperação. Um dos desafios é a percepção material, por parte de todos os profissionais envolvidos, das reais falhas e necessidades da população. Muito já se caminhou a partir da constitucionalização do SUS, e não podemos nos distanciar de seus princípios fundamentais, de forma que os rumos sejam realmente garantidores de acesso universal à saúde e à Justiça. 


\section{Referências}

BARROSO, L. R. Da falta de efetividade à judicialização excessiva: direito à saúde, fornecimento gratuito de medicamentos e parâmetros para a atuação judicial. Revista de Direito - v. 63, p. 320-344, 2008. Disponível em: <http://www.rj.gov.br/c/document_library/ get_file?uuid=ddd94821-04ab-4710-a3c1-0b61193e87ac\&groupId=132971 >. Acesso em: 03 ago. 2018.

BOURDIEU, P. O poder simbólico. Trad. Fernando Tomaz. 3. ed. Rio de Janeiro: Bertrand Brasil, 2000.

MESSEDER, A.M.; OSORIO-DE-CASTRO, C.G.S.; LUIZA, V.L. Mandados judiciais como ferramenta para garantia do acesso a medicamentos no setor público: a experiência do Estado do RJ, Brasil. Cad. Saúde Pública, São Paulo, v. 21, n. 2, p. 525-534, mar./abr. 2005. Disponível em: <http://www.med-informatica.net/OBSERVAMED/PFNyLeyMedicamento/ Costos_medicamentos_brazil.pdf $>$.

NAP-DISA/USP. Cepedisa. Opinião legal. São Paulo: USP, 2015. Disponível em <http:// napdisa.prp.usp.br/wp-content/uploads/2016/12/OPINIAO-LEGAL-Competencia-ComumSaude-final.pdf $>$. Acesso em: 19 abr. 2018.

PEPE, V.L.E. et al. Caracterização de demandas judiciais de fornecimento de medicamentos “essenciais” no Estado do RJ, Brasil. Cad. Saúde Pública, São Paulo, v. 26, n. 3, p. 461-471, 2010. Disponível em: <http://www.scielo.br/pdf/csp/v26n3/04.pdf>. http://dx.doi.org/10.1590/ S0102-311X2010000300004.

PINTO, C.D.B.S.; OSORIO-DE-CASTRO, C.G.S. Gestão da Assistência Farmacêutica e demandas judiciais em pequenos municípios brasileiros: um estudo em MS. Saúde Debate, Rio de Janeiro, v. 39, n. esp., p. 171-183, 2015. Disponível em: <http://www.scielo.br/ pdf/sdeb/v39nspe/0103-1104-sdeb-39-spe-00171.pdf>. http://dx.doi.org/10.5935/01031104.2015S005152.

SANTOS, B.S. Para uma revolução democrática da justiça. 3. ed. Rio de Janeiro: Cortez, 2012.

SARLET, I.W. A titularidade simultaneamente individual e transindividual dos direitos sociais analisada à luz do exemplo do direito à proteção e promoção da saúde. Direitos Fundamentais e Justiça, n.10, p. 205-227, jan. 2010.

SCHEFFER, M. Coquetel: a incrível história dos antirretrovirais e do tratamento da Aids no Brasil. São Paulo: Hucitec; Sobravime, 2012.

SUPERIOR TRIBUNAL DE JUSTIÇA - STJ. Primeira Seção define requisitos para fornecimento de remédios fora da lista do SUS. 25/04/2018. Disponível em: <http://www.stj.jus.br/sites/ STJ/default/pt_BR/Comunica\%C3\%A7\%C3\%A3o/noticias/Not\%C3\%ADcias/Primeira$\mathrm{Se} \% \mathrm{C} 3 \% \mathrm{~A} 7 \% \mathrm{C} 3 \% \mathrm{~A} 30$-define-requisitos-para-fornecimento-de-rem\%C3\%A9dios-fora-dalista-do-SUS>. Acesso em: 27 abr. 2018. 
TRIBUNAL DE JUSTIÇA DO ESTADO DO RIO DE JANEIRO - TJRJ. Aviso Conjunto TJ / COJES n. 15/2017. Rio de Janeiro: DJ/RJ, 10 (66), 14/12/2017. Disponível em: <http://www. tjrj.jus.br/documents/10136/18972/aviso-conjunto-tj-cojes-15-2017-fazendario.pdf $>$. Acesso em: 27 abr. 2018.

VENTURA, M. O processo decisório judicial e a assessoria técnica: a argumentação jurídica e médico-sanitária na garantia do direito à assistência terapêutica no Sistema Único de Saúde. Tese (Doutorado em Ciências na área de Saúde Pública) - ENSP/Fiocruz, Rio de Janeiro, 2012. Disponível em: <http://bvsms.saude.gov.br/bvs/publicacoes/premio2012/doutorado/ Miriam\%20Ventura\%20da\%20Silva.pdf>.

VIANNA, L.W. et al. A judicialização da política e das relações sociais no Brasil. Rio de Janeiro: Revan, 1999.

Luciana Simas - Doutora pelo Programa de Pós-Graduação em Bioética, Ética Aplicada e Saúde Coletiva da Universidade Federal do Rio de Janeiro (UFRJ), com intercâmbio na University of Florida - Levin College of Law; mestre em Direito e Sociologia pela Universidade Federal Fluminense. Advogada. Rio de Janeiro/RJ, Brasil E-mail: lucianasiams06@gmail.com

Miriam Ventura - Doutora e mestre em Saúde Pública pela Escola Nacional de Saúde Pública/ Fiocruz. (ENSP/Fiocruz). Professora adjunta do Instituto de Estudos em Saúde Coletiva da Universidade Federal do Rio de Janeiro. Rio de Janeiro/RJ, Brasil. 